\title{
ANÁLISE DA FORMA DE ORGANIZAÇÃO ESTRATÉGICA DO POEMA “POBRE ALIMÁRIA", DE OSWALD DE ANDRADE
}

\author{
ANALYSIS OF STRATEGIC ORGANIZATIONAL FORM OF THE POEM "POBRE \\ ALIMÁRIA", BY OSWALD DE ANDRADE
}

\author{
Gustavo Ximenes Cunha \\ Universidade Federal de Alfenas
}

RESUMO: Este trabalho estuda o poema "Pobre alimária", de Oswald de Andrade, com base no Modelo de Análise Modular do Discurso. Para mostrar que o poema constitui uma crítica à poesia oficial do início do século XX, analisamos a forma de organização estratégica do poema, revelando como o autor faz a gestão das relações de faces, territórios e lugares. Ao final do percurso de análise, constatamos que essas relações estão materializadas no texto, o qual pode ser considerado um importante documento histórico, porque revela as tensões culturais e sociais de sua época.

PALAVRAS-CHAVE: Oswald de Andrade; estratégia; modularidade.

ABSTRACT: This paper studies the poem "Pobre alimária" by Oswald de Andrade, based on Modular Approach of Discourse Analysis. To show that the poem is a critique of the official poetry of the early 20th century, we analyze the strategic organization of the poem, revealing how the author makes the management of relations of faces, places and territories. At the end of the analysis, we found that these relationships are materialized in the text, which can be considered an important historical document, because it reveals the cultural and social tensions of his time.

KEY-WORDS: Oswald de Andrade; strategy; modularity.

No início do século $X X$, a estética parnasiana mantinha-se forte como o molde da linguagem literária, como nota Campos (1990, p. 8) ao se referir a esse momento: "Rui Barbosa, 'a águia de Haia'; Coelho Neto, 'o último Heleno'; Olavo Bilac, 'o príncipe dos poetas' eram os deuses incontestes de um Olimpo oficial, no qual o Pégaso parnasiano arrastava seu pesado caparazão metrificante". Nesse contexto, a poesia de Oswald de Andrade representou um ponto importante de ruptura em relação à poesia considerada oficial, refletindo, por isso mesmo, mudanças sociais e culturais por que o país vinha passando.

Neste trabalho, o objetivo é mostrar, por meio de análise textual-discursiva, que, com o poema "Pobre alimária", integrante do livro Pau-Brasil, de 1925, Oswald de Andrade critica a poesia oficial de sua época (parnasiana e simbolista), defendendo uma nova 


\title{
Revista do SELL
}

v. $4, n^{\circ} .2$

ISSN: $1983-3873$

estética, uma nova maneira de se fazer poesia. Essa defesa, no entanto, não ocorre de maneira panfletária, por meio de discurso que atacasse diretamente o modo estabelecido de se fazer poesia, tal como ocorre no "Manifesto da Poesia Pau-Brasil" do mesmo autor. A estratégia adotada por Oswald de Andrade em "Pobre alimária" e em grande parte dos poemas de Pau-Brasil é a de já apresentar a poesia que essa nova estética permitia realizar.

Esse ataque indireto à poesia oficial do início do século XX justifica a análise textualdiscursiva dos procedimentos adotados por Oswald de Andrade para compor "Pobre alimária". Uma vez que os planos de organização dos textos são sensíveis ao seu contexto de produção (Bronckart, 2007), é de se esperar que as tensões sociais e culturais do contexto de Oswald de Andrade estejam materializadas ou inscritas em "Pobre Alimária", que reproduzimos a seguir:

\author{
Pobre alimária \\ O cavalo e a carroça \\ Estavam atravancados no trilho \\ E como o motorneiro se impacientasse \\ Porque levava os advogados para o escritório \\ Desatravancaram o veículo \\ E o animal disparou \\ Mas o lesto carroceiro \\ Trepou na boleia \\ E castigou o fugitivo atrelado \\ Com um grandioso chicote.
}

Tendo em vista o interesse em estudar os procedimentos de construção do poema, a sua análise será realizada com base nos postulados teóricos e metodológicos de um modelo da Análise do Discurso, o Modelo de Análise Modular do Discurso, o qual será apresentado rapidamente no próximo item. Posteriormente, será desenvolvida a análise do poema, a qual, com base no modelo modular, será feita em etapas, cada uma das quais descrevendo os módulos e as formas de organização necessárias à compreensão do poema.

\section{Modelo de Análise Modular do Discurso}

Em sua versão atual (Roulet; Filliettaz; Grobet, 2001, Marinho; Pires; Villela, 2007), o Modelo de Análise Modular do Discurso constitui um instrumento de análise que integra e 


\section{Revista do SELL}

v. $4, n^{\circ} .2$

ISSN: $1983-3873$

articula, em uma perspectiva cognitivo-interacionista, as dimensões linguística, textual e situacional da organização do discurso. Porque integra diferentes dimensões, esse é um modelo global e abrangente de compreensão da complexidade discursiva.

Adotando a modularidade como perspectiva metodológica, o modelo modular considera ser possível descrever, por exemplo, o léxico de uma língua independentemente da situação de interação em que ele é utilizado, bem como descrever as estruturas sintáticas de um texto sem fazer referência à estrutura conceitual que subjaz a esse texto. Descritas de modo independente as informações que participam da organização do discurso, 0 modelo postula ainda que essas informações podem ser combinadas, a fim de se descreverem os diferentes aspectos envolvidos na produção e na interpretação dessa organização complexa que é o discurso.

Conforme a metodologia adotada pelo modelo modular, identificam-se, inicialmente, os módulos que entram na composição do discurso ${ }^{1}$. Posteriormente, procura-se mostrar como as informações resultantes do estudo dos módulos se combinam em formas de organização do discurso ${ }^{2}$.

Neste trabalho, para mostrar que, em "Pobre alimária", Oswald de Andrade critica a poesia oficial de sua época (parnasiana e simbolista), defendendo uma nova estética, impulsionado pelo momento histórico, analisaremos a forma de organização estratégica do poema. Como será exposto mais detalhadamente adiante, essa forma de organização descreve a maneira como os interactantes coordenam as relações de faces, territórios e lugares no discurso. Para analisar a forma de organização estratégica de "Pobre alimária", combinaremos informações do módulo referencial e das formas de organização relacional, informacional, tópica, sequencial e composicional.

\footnotetext{
${ }^{1}$ Nessa abordagem, cada dimensão do discurso se constitui de módulos. Assim, a dimensão linguística se constitui dos módulos lexical e sintático; a dimensão textual se constitui do modulo hierárquico; e a dimensão situacional se constitui dos módulos interacional e referencial.

${ }^{2}$ No modelo modular, distinguem-se dois tipos de formas de organização: as elementares e as complexas. As formas de organização elementares (fono-prosódica ou gráfica, semântica, relacional, informacional, enunciativa, sequencial e operacional) resultam da combinação ou acoplagem de informações extraídas dos módulos. Já as formas de organização complexas (periódica, tópica, polifônica, composicional e estratégica) resultam da combinação ou acoplagem de informações extraídas dos módulos e das formas de organização elementares e/ou complexas.
} 


\section{Revista do SELL}

v. $4, n^{\circ} .2$

ISSN: $1983-3873$

Apenas a consideração progressiva e não-simultânea de todas essas informações permitirá um estudo, ao mesmo tempo, rigoroso e aprofundado do poema. Assim, cada item a seguir estuda separadamente o módulo referencial e as formas de organização mencionadas. Ao final, as informações resultantes desses estudos parciais serão combinadas, na análise da forma de organização estratégica, para compreender como Oswald de Andrade, em "Pobre alimária", interage com o leitor de seu tempo, fazendo a gestão das relações de faces, territórios e lugares.

\section{Módulo referencial}

Esse módulo estuda as relações que o discurso mantém com o mundo no qual é produzido, bem como as relações que mantém com os mundos que representa (Filliettaz, 2000). Um dos instrumentos de que esse modelo se vale para estudar o mundo em que discurso se insere é o enquadre acional. Considerando que o engajamento dos participantes do discurso não acontece de forma desorganizada, esse enquadre busca reconstruir as propriedades ligadas às instâncias agentivas de uma interação verbal efetiva, as quais são responsáveis em grande medida pela regulação das produções verbais (Filliettaz, 2000). No enquadre acional, a descrição das propriedades de uma situação específica se faz por meio da articulação de quatro parâmetros, que são os enjeux comuns, as ações participativas, as posições acionais e os complexos motivacionais.

Os enjeux comuns se referem à finalidade compartilhada pelos agentes, em torno da qual eles estruturam seu engajamento ou associação momentânea. As ações participativas dizem respeito aos objetivos individuais de cada um dos agentes ou às "parcelas interdependentes de responsabilidade que cabem a cada um dos interactantes na emergência de um enjeu comum" (Roulet; Filliettaz; Grobet, 2001, p. 114). Já as posições acionais se referem à representação das identidades participativas que são efetivamente assumidas pelos agentes. Para se chegar à posição acional dos participantes da interação, é preciso levar em conta o status social de cada um deles, os papéis praxeológicos ligados às ações participativas, bem como as faces e os territórios em jogo. Os complexos motivacionais, por fim, remetem às razões exteriores à situação que levam cada um dos agentes àquele engajamento específico. 


\section{Revista do SELL}

v. $4, n^{\circ} .2$

ISSN: $1983-3873$

As noções de face e de território são especialmente relevantes para o estudo da forma de organização estratégica. Goffman (2011, p. 13-14) define a noção de face como "o valor social positivo que uma pessoa efetivamente reivindica para si mesma através da linha que os outros pressupõem que ela assumiu durante um contato particular". Já a noção de território diz respeito aos direitos que cada pessoa reivindica e à defesa desses mesmos direitos. Segundo Goffman (1973), o território se refere não só ao território físico, à "porção de espaço que cerca um indivíduo" (p. 44), mas às informações às quais o indivíduo tenta controlar o acesso, bem como ao direito que tem o indivíduo de controlar quem pode Ihe endereçar a fala.

Como resultado da combinação desses parâmetros, o enquadre acional da interação mediada pelo poema "Pobre alimária" pode ser representado da seguinte forma:

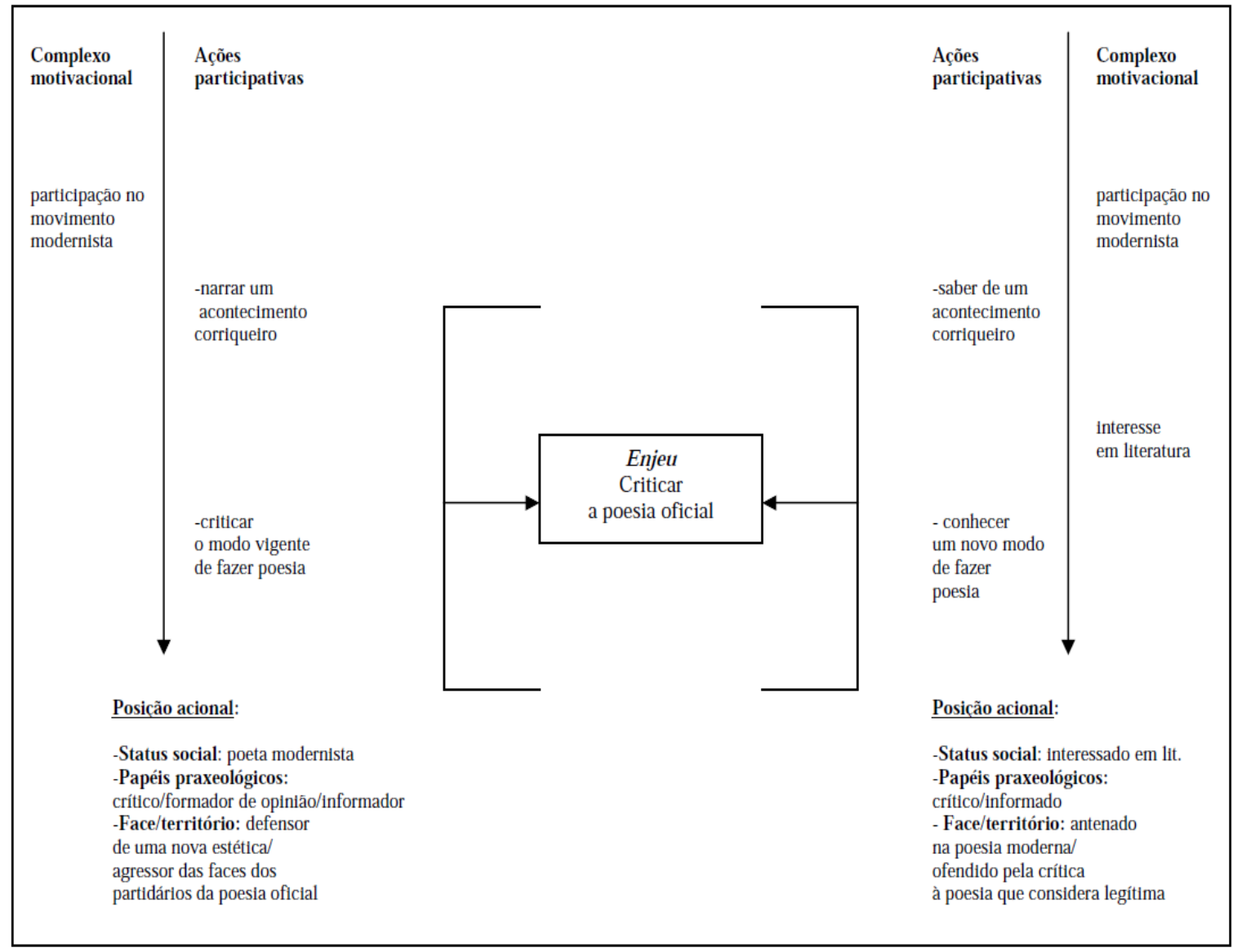

Figura 1 - enquadre acional de "Pobre alimária"

Oswald de Andrade produz "Pobre alimária", porque participa do movimento modernista. Essa participação é o motivo externo à interação que o leva a produzir o poema. Por sua vez, o leitor do início do século XX lê o poema porque se interessa por literatura ou porque, além de ter esse interesse, também é um participante do movimento modernista. 


\section{Revista do SELL}

v. $4, n^{\circ} .2$

ISSN: $1983-3873$

Guiada por esses motivos, a relação entre autor e leitor se justifica por uma finalidade comum (enjeu), que é criticar a poesia oficial ou considerada legítima no início do século XX. Ou seja, essa é a finalidade que justifica a interação, associando momentaneamente autor e leitor. Dessa forma, considerando o contexto em que o poema foi produzido, entendemos que Oswald de Andrade não parece ter como finalidade primeira fazer o leitor passar o tempo, entretendo-o ou proporcionando a ele a fruição de uma experiência estética. Ao contrário, a finalidade mais imediata parece ser a de criticar o fazer poético considerado canônico em sua época, para impor uma nova concepção de arte.

No poema, as ações participativas que o autor realiza são basicamente duas: narrar um acontecimento corriqueiro e, ao realizar essa ação, criticar indiretamente o modo vigente de fazer poesia, que jamais se ocuparia da narração de um acontecimento trivial do cotidiano. No que se refere às posições acionais, o status social dos interactantes é estável ao longo da interação, já que o autor assume o status de poeta modernista, ao passo que o leitor com quem dialoga no contexto de produção do poema assume o status de interessado em literatura. Mas as ações que realizam obrigam-nos a assumirem papéis praxeológicos mais locais. Assim, ao narrar um acontecimento corriqueiro, o autor assume o papel de informador. Porém, como indiretamente ele critica o modo vigente de fazer poesia em sua época, ele também assume o papel de crítico e de formador de opinião. Nesse contexto, o autor, ao interagir com o leitor, procura construir a imagem (face) de um defensor de uma nova estética e, ao mesmo tempo, agredir a face dos partidários da poesia oficial.

As informações desse enquadre serão retomadas ao final do percurso de análise, no estudo da forma de organização estratégica.

\section{Forma de organização relacional}

$\mathrm{Na}$ forma de organização relacional, estudam-se as relações de discurso e seus eventuais marcadores (conectores e estruturas sintáticas). A base desse estudo são as informações do módulo hierárquico. Nesse módulo, considera-se que toda interação verbal se caracteriza por um processo de negociação em que os interactantes iniciam proposições, reagem a elas e as ratificam. $O$ módulo hierárquico define as categorias e as regras que 


\section{Revista do SELL}

v. $4, n^{\circ} .2$

ISSN: $1983-3873$

permitem gerar as estruturas hierárquicas das trocas, constituintes textuais que materializam esse processo de negociação, bem como das intervenções, constituintes que integram as trocas e que materializam cada fase (proposição, reação e ratificação) desse processo. (Roulet; Filliettaz; Grobet, 2001, Marinho, 2002, Cunha, 2012).

$\mathrm{Na}$ forma de organização relacional, as informações do módulo hierárquico são combinadas com informações dos módulos lexical, sintático e referencial. Um dos objetivos dessa forma de organização é identificar as relações interativas genéricas entre os constituintes da estrutura hierárquica e informações da memória discursiva ${ }^{3}$ com base em uma lista reduzida de categorias. Distinguem-se oito categorias genéricas de relações interativas: argumento, contra-argumento, reformulação, topicalização, sucessão, preparação, comentário e clarificação.

Consideramos que, em relação ao poema "Pobre alimária", a poesia oficial da época de sua produção (a concepção do fazer poético da época, sua temática, seus autores consagrados, seus procedimentos de composição) constitui a primeira fase de um processo de negociação. Dessa forma, essa poesia constitui a proposição, em relação à qual Oswald de Andrade reage escrevendo o poema, em que expressa uma outra concepção de poesia. Embora de extensão reduzida, essa reação apresenta uma estrutura hierárquico-relacional complexa, tendo em vista o processo de negociação de que participa. Assim, para fazer frente à poesia de sua época, o autor constrói um poema cujos constituintes textuais se articulam predominantemente por relações de argumento, como mostra sua estrutura hierárquico-relacional ${ }^{4}$.

\footnotetext{
${ }^{3}$ A memória discursiva é definida como o conjunto de saberes partilhados pelos interlocutores (Roulet; Filliettaz; Grobet, 2001).

${ }^{4}$ Essa estrutura se compõe das seguintes informações: ato $=A$; intervenção = $\mathrm{l}$; principal $=p$; subordinado $=\mathrm{s} ;$ preparação $=$ prep; argumento $=$ arg; contra-argumento $=\mathrm{c}-\mathrm{a}$; sucessão $=$ suc.
} 


\section{Revista do SELL}

v. $4, n^{\circ} .2$

ISSN: $1983-3873$

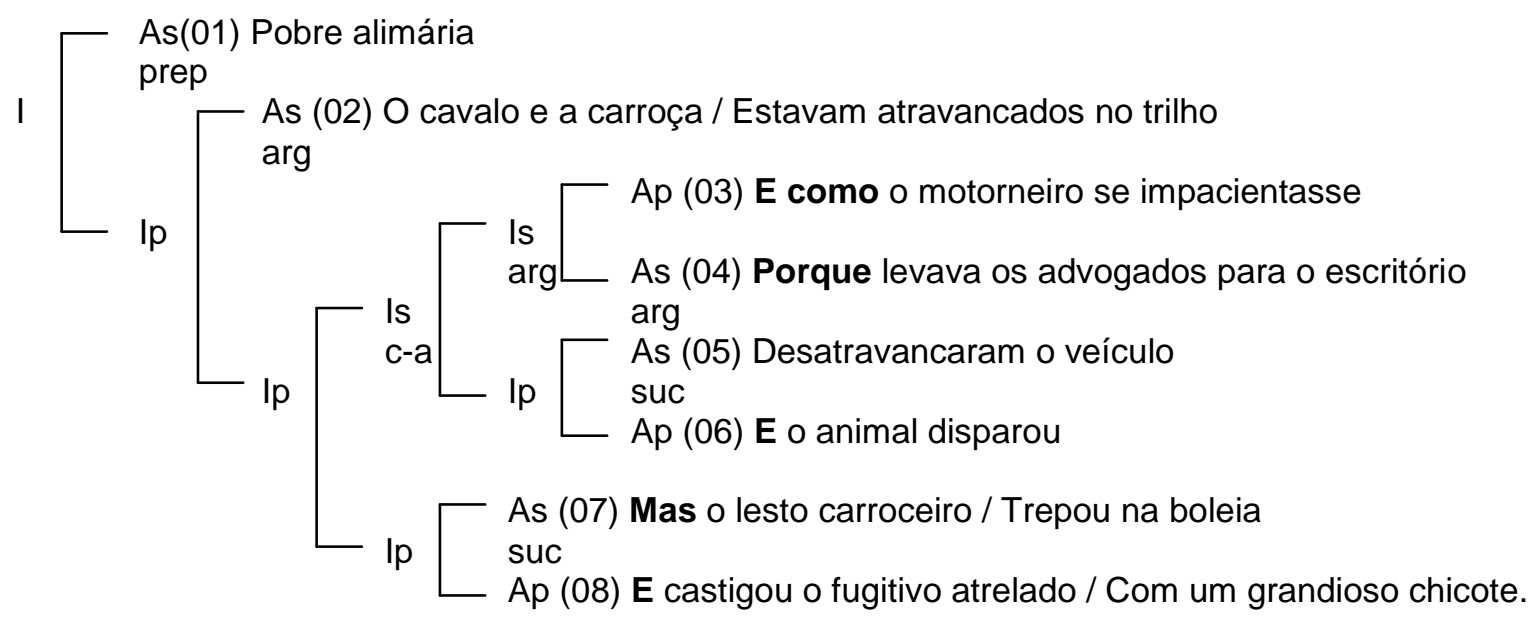

Figura 2 - estrutura hierárquico-relacional de "Pobre alimária"

A construção do poema é complexa, porque se dá predominantemente pelo recurso das subordinações retroativas. Nessa forma de construção textual, um constituinte é subordinado pelo constituinte seguinte. Por exemplo, o ato (02) é subordinado pela lp (0308). No interior dessa Ip, a intervenção (03-06) é subordinada pela Ip (07-08). Com esse recurso, o autor indica que o ato mais relevante do poema é o Ap (08), já que esse é um ato principal que em diferentes níveis da estrutura participa da elaboração de intervenções também principais. Nesse ato, o autor aborda o castigo sofrido pelo cavalo.

E, como revelam os conectores em negrito, a maior parte das relações de discurso do poema é marcada. A atuação de um conector na marcação de uma relação auxilia a limitar diferentes possibilidades de interpretação, sinalizando que entre o ato que introduz e a informação em que se articula há uma relação de discurso bem definida (Marinho, 2002). Ao marcar a estrutura do poema com vários conectores, Oswald de Andrade constrói um texto cujo mundo representado dá pouca margem à multiplicidade de interpretações, afastando-se, portanto, da estética simbolista, por exemplo, e aproximando-se do discurso jornalístico.

\section{Formas de organização informacional e tópica}

O estudo da forma de organização informacional tem os objetivos de analisar a estrutura informacional de cada ato e descrever a sua inserção na estrutura do discurso, por meio das formas de progressão informacional que se observam na sucessão dos atos. 


\section{Revista do SELL}

v. $4, n^{\circ} .2$

ISSN: $1983-3873$

Esse estudo se realiza por meio da descrição dos encadeamentos de cada ato em informações da memória discursiva. Assim, cada ato ativa uma informação, que se ancora em pelo menos uma informação ou ponto de ancoragem da memória discursiva. O ponto de ancoragem imediato é o tópico, que diz respeito à informação mais diretamente acessível da memória discursiva na qual o ato se encadeia. Os tópicos podem ser verbalizados por traços anafóricos, como pronomes ou expressões definidas. Esses traços são chamados de traços tópicos (Grobet, 2000, Cunha, 2008).

Essa forma de organização se ocupa ainda dos tipos de progressões informacionais por meio dos quais os atos se ligam aos tópicos. Os tipos de progressões considerados pelo modelo modular são: encadeamento ou progressão linear (ocorre quando o tópico de um ato tem origem na informação que acaba de ser ativada); encadeamento ou progressão com tópico constante (ocorre quando uma sucessão de atos se ancora num mesmo tópico); encadeamento à distância (ocorre quando o tópico de um ato tem origem não no ato precedente, mas num ato mais distante) (Marinho, 2002, Cunha, 2008).

O quadro abaixo apresenta a estrutura informacional do poema "Pobre alimária".

\begin{tabular}{|l|ll|}
\hline (01) Pobre alimária & \\
\hline $\begin{array}{l}\text { (02) O cavalo [pobre alimária] e a carroça / } \\
\text { Estavam atravancados no trilho }\end{array}$ & Progressão linear \\
\hline $\begin{array}{l}\text { (03) E como o motorneiro [no trilho do } \\
\text { bonde] se impacientasse }\end{array}$ & Progressão linear \\
\hline $\begin{array}{l}\text { (04) (motorneiro) Porque levava os } \\
\text { advogados para o escritório }\end{array}$ & Progressão linear \\
\hline $\begin{array}{l}\text { (05) (advogados e transeuntes) } \\
\text { Desatravancaram o veículo }\end{array}$ & Progressão linear \\
\hline $\begin{array}{l}\text { (06) E o animal [o cavalo] disparou } \\
\text { (07) Mas o lesto carroceiro } \\
\text { [carroça/veículo] / Trepou na boleia }\end{array}$ & $\begin{array}{l}\text { Encadeamento } \\
\text { distância }\end{array}$ \\
\hline $\begin{array}{l}\text { (08) oncadeamento carroceiro) E castigou o fugitivo } \\
\text { atrelado / Com um grandioso chicote. }\end{array}$ & Progressão linear \\
\hline
\end{tabular}

Figura 3 - estrutura informacional de "Pobre alimária"

No poema, a maior parte dos atos tem como tópico a informação "Pobre alimária", ativada primeiramente no título e reativada posteriormente por meio das expressões "o cavalo", "o animal" e "o fugitivo atrelado". A manutenção desse conceito no foco de atenção do leitor revela uma concepção de arte que contrasta fortemente com a estética parnasiana. Nessa estética, jamais um simples animal seria escolhido para ser o tópico da maior parte dos atos de um poema. 


\section{Revista do SELL}

v. $4, n^{\circ} .2$

ISSN: $1983-3873$

Como é típico das sequências narrativas (Grobet, 1999), predominam no poema os encadeamentos por progressão linear. Como exemplo, o ato (04) tem como tópico "motorneiro", informação ativada no ato (03). Esse tipo de encadeamento auxilia na compreensão do texto, porque exige pouco esforço de processamento por parte do leitor, que, para compreender de que trata $o$ ato, mobiliza informação ativada no ato precedente. Além disso, construindo assim a organização informacional do poema, o poeta torna o texto mais simples, sem as inversões sintáticas e textuais que caracterizam os poemas parnasianos e simbolistas.

A forma de organização informacional constitui a primeira etapa do estudo da forma de organização tópica. Um dos objetivos dessa forma de organização é estudar a hierarquia das informações ativadas ao longo do discurso, verificando o grau de saliência dessas informações na memória discursiva. Esse estudo se faz com base na combinação da estrutura informacional com a estrutura hierárquico-relacional, estudada no item anterior. O resultado dessa combinação pode ser visualizado na estrutura abaixo:

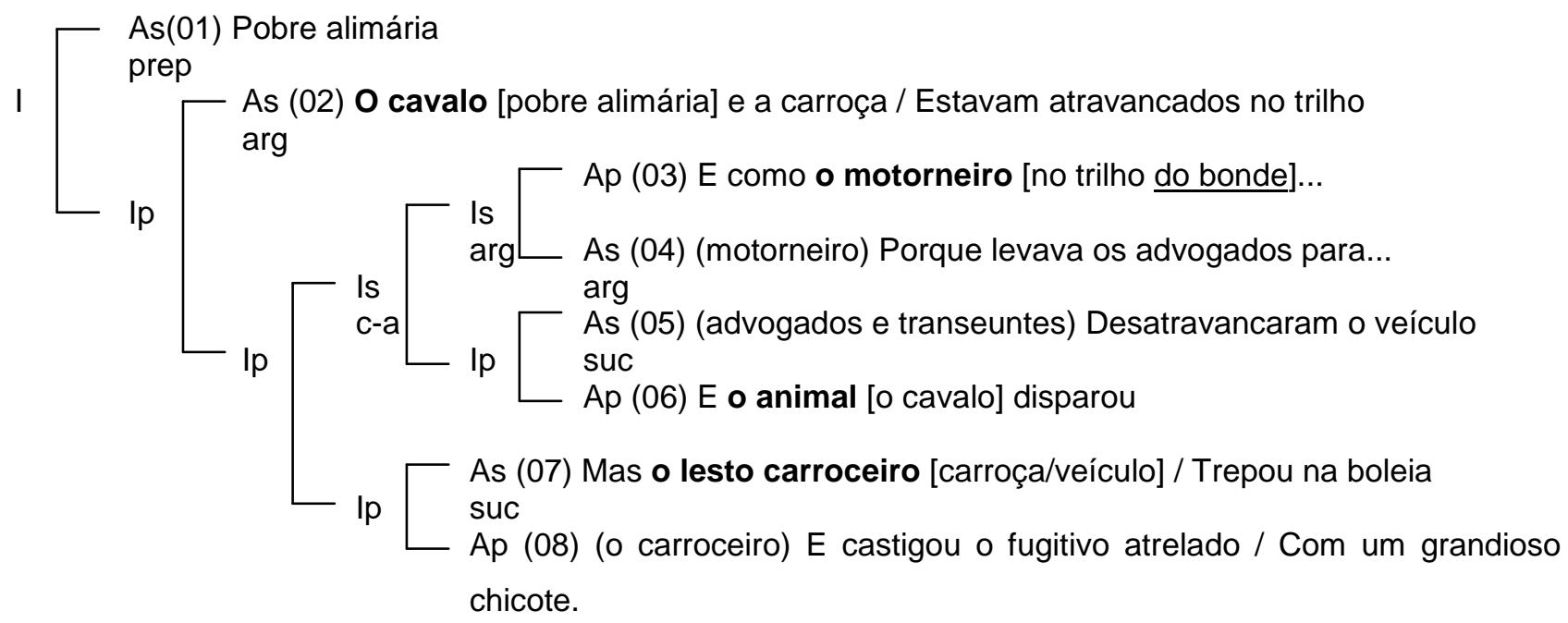

Figura 4 - acoplagem das estruturas hierárquico-relacional e informacional de "Pobre alimária"

Essa estrutura revela que as informações mais salientes na memória discursiva são aquelas ativadas no ato (08) ("E castigou o fugitivo atrelado / Com um grandioso chicote"), ato que finaliza o texto. Isso porque, tendo em vista o processo de construção textual por subordinações retroativas, esse é o ato mais elevado na hierarquia do poema. Não por 


\section{Revista do SELL}

v. $4, n^{\circ} .2$

ISSN: $1983-3873$

acaso, "o fugitivo atrelado" constitui uma recategorização de "Pobre alimária", informação que, por ter sido ativada já no título, pode ser compreendida como a entidade tópica do texto ${ }^{5}$.

\section{Formas de organização sequencial e composicional}

A forma de organização sequencial se ocupa basicamente da segmentação do discurso em sequências (narrativas, descritivas e deliberativas). Para isso, busca, de um lado, definir uma tipologia discursiva que possa ser aplicada a todas as produções linguageiras e, de outro, extrair as sequências discursivas em que os tipos de discurso se atualizam (Filliettaz, 1999, Cunha, 2010, 2013).

O poema "Pobre alimária" constitui uma sequência que pertence ao tipo narrativo. No modelo, esse tipo é definido como uma cadeia culminativa de acontecimentos que se compõe dos episódios estado inicial, complicação, reação, resolução e estado final (Roulet; Filliettaz; Grobet, 2001). A hipótese dessa cadeia repousa sobre a ideia de que toda história pressupõe uma tensão entre acontecimentos desencadeadores e acontecimentos conclusivos, a qual decorre da transformação dos personagens e da situação em que se encontram inicialmente implicados (Cunha, 2009). A análise de "Pobre alimária" do ponto de vista sequencial pode ser representada da seguinte maneira.

\begin{tabular}{|l|l|}
\hline Sumário & (01) Pobre alimária \\
\hline $\begin{array}{l}\text { Estado } \\
\text { inicial }\end{array}$ & $\begin{array}{l}\text { (02) O cavalo e a carroça / Estavam } \\
\text { atravancados no trilho }\end{array}$ \\
\hline Complicação & $\begin{array}{l}\text { (03) E como o motorneiro se impacientasse } \\
\text { (04) Porque levava os advogados para o } \\
\text { escritório }\end{array}$ \\
\hline Reação & $\begin{array}{l}\text { (05) Desatravancaram o veículo } \\
\text { (06) E o animal disparou }\end{array}$ \\
\hline Resolução & $\begin{array}{l}\text { (07) Mas o lesto carroceiro / Trepou na boleia } \\
\text { (08) E castigou o fugitivo atrelado / Com um } \\
\text { grandioso chicote. }\end{array}$ \\
\hline Estado final & $\varnothing$ Edepois disso todos foram embora. \\
& $\begin{array}{l}\text { E cada um foi para o seu trabalho. } \\
\text { E todos recriminaram a atitude do carroceiro. }\end{array}$ \\
\hline
\end{tabular}

Figura 5 - análise sequencial de "Pobre alimária"

\footnotetext{
${ }^{5} \mathrm{O}$ estudo da entidade tópica de um texto é um dos objetivos da forma de organização tópica e se faz com base na acoplagem da estrutura informacional e da estrutura conceitual (Grobet, 2000, Cunha, 2009). Por motivo de espaço e tendo em vista os objetivos desta análise, esse estudo não será desenvolvido aqui.
} 


\section{Revista do SELL}

v. $4, n^{\circ} .2$

ISSN: $1983-3873$

No poema, o título constitui um sumário, porque antecipa quem é a personagem principal e traz um adjetivo, "pobre", que condensa os sofrimentos ou maus tratos de que ela será alvo. O estado inicial apresenta uma situação de equilíbrio ("O cavalo e a carroça/Estavam atravancados no trilho"). Na complicação, essa situação sofre uma mudança, porque vai opor a carroça ao bonde, o qual se vê impedido de passar pelo trilho. É essa oposição entre um veículo tradicional e um veículo moderno para o momento de produção do poema que permite a Schwarz (1987, p. 15) ler esse poema como o retrato do conflito de duas realidades distintas: "De um lado, o bonde, os advogados, o motorneiro e os trilhos; do outro, o cavalo, a carroça e os carroceiro: são mundos, tempos e classes sociais contrastantes, postos em oposição." ${ }^{\text {. }}$ Na reação, para que o bonde possa passar, a carroça foi desatravancada, "e o animal disparou". Na resolução, o problema se resolve com a punição do animal, a qual justifica o adjetivo "pobre" no sumário. O poema não traz um estado final, o qual, no entanto, poderia ser elaborado de diferentes modos, como exemplificado na última linha do quadro.

Essa estrutura narrativa, que representa um acontecimento corriqueiro do dia a dia da São Paulo do início do século XX, contrasta fortemente com a estrutura de poemas narrativos parnasianos, os quais abordavam acontecimentos vividos por personagens históricos (heróis nacionais) ${ }^{7}$. Em "Pobre alimária", os personagens são integrantes do povo (o carroceiro, os advogados, o motorneiro), e a personagem principal é um cavalo puxador de carroça. Dessa forma, Oswald de Andrade opõe dois mundos, como propôs Schwarz, para opor duas formas de fazer poesia, a sua e a dos poetas oficiais, evidenciando, assim, conflitos sociais e culturais de seu tempo.

A forma de organização sequencial constitui a primeira etapa do estudo da forma de organização composicional. Nessa forma de organização, um dos objetivos é realizar um estudo pormenorizado das propriedades formais das sequências discursivas, investigando as suas especificidades linguísticas (lexicais e sintáticas) e hierárquico-relacionais (Cunha, 2013). Assim, para o modelo modular, uma mesma sequência pode apresentar

\footnotetext{
${ }^{6}$ Uma leitura semelhante desse poema é feita por Santiago (2006, p. 186): "Oswald narrava a modernidade de São Paulo pelo conflito entre o carroceiro (o Brasil arcaico) e o motorneiro do bonde (o Brasil moderno)"

${ }^{7}$ Basta pensar, por exemplo, em "O caçador de esmeraldas", de Olavo Bilac.
} 


\section{Revista do SELL}

v. $4, n^{\circ} .2$

ISSN: $1983-3873$

uma quantidade maior ou menor de marcas referentes a três categorias de efeitos composicionais: os argumentativos, os autotélicos e os narrativos.

Os efeitos argumentativos se manifestam em sequências que apresentam conectores argumentativos, contra-argumentativos e reformulativos, assim como expressões modais, vocabulário axiológico e verbos flexionados no presente e no futuro do presente. Já os efeitos autotélicos se manifestam em sequências que apresentam diferentes formas de paralelismos fônicos, lexicais, semânticos, sintáticos e textuais. Por fim, os efeitos narrativos podem se manifestar em quaisquer sequências e não só nas narrativas, desde que apresentem organizadores e conectores temporais, bem como verbos flexionados no pretérito perfeito, no imperfeito, no mais-que-perfeito e no futuro do pretérito.

Em "Pobre alimária", os efeitos argumentativos predominam e se manifestam pela frequência de relações de discurso argumentativas e pelos conectores que marcam essas relações (e como, porque). A presença dos adjetivos também merece destaque, porque itens como pobre, lesto e grandioso revelam o ponto de vista do narrador em relação aos conceitos ativados pelos substantivos que determinam (alimária, carroceiro e chicote, respectivamente). Da mesma forma, o uso do verbo no subjuntivo (impacientasse) revela a aproximação do poema de gêneros mais monitorados, como os do jornalismo, e o seu afastamento de gêneros menos monitorados, como os do cotidiano.

Os efeitos autotélicos se manifestam basicamente na segmentação do poema em versos. A ausência de elementos formais típicos de poemas, como versos rimados e marcação rítmica rígida (Rufino, 2011), tem como finalidade criar um efeito de prosa (jornalística). Já os efeitos narrativos se manifestam pelo emprego de verbos no pretérito imperfeito para expressar acontecimentos estáticos (estados) e de verbos no perfeito para expressar acontecimentos dinâmicos (ações).

\section{Forma de organização estratégica}

Após o estudo separado do módulo referencial e das formas de organização relacional, informacional, tópica, sequencial e composicional, esta etapa da análise combina todas essas informações no estudo da forma de organização estratégica, a qual, neste trabalho, 


\section{Revista do SELL}

v. $4, n^{\circ} .2$

ISSN: $1983-3873$

tem como fim investigar as relações de faces, territórios e lugares entre Oswald de Andrade e os leitores do início do século XX.

A forma de organização estratégica tem como objetivo estudar o modo como os interactantes coordenam as relações de faces, territórios e lugares no discurso, passando da descrição à explicação dos comportamentos dos interactantes em termos de estratégias (Burger, 1995). No estudo da gestão das relações de faces e territórios, combinam-se informações acerca dessas noções, oriundas do enquadre acional, com informações de outros módulos e formas de organização, para verificar, em especial, como os interactantes realizam os processos de figuração, isto é, as estratégias para reduzir as ameaças às suas faces e aos seus territórios.

Já o estudo das relações de lugares trata da relação vertical ou de dominância entre os interactantes, durante o desenvolvimento da interação ${ }^{8}$. A noção de lugar não é uma noção primitiva, porque, ao contrário das noções de face e de território, cujo estudo se realiza em um módulo (o referencial), o lugar é uma noção cuja análise resulta da combinação de informações de diferentes módulos e formas de organização. Assim, a percepção do lugar ocupado por um interactante em determinado momento da interação implica mobilizar informações de diferentes planos da organização discursiva.

Em "Pobre alimária", Oswald de Andrade defende uma nova estética, produzindo um poema de cuja composição participam elementos que contrariam a concepção vigente de poesia em sua época. Diferentemente de um poeta parnasiano, ele tematiza pessoas comuns envolvidas num acontecimento trivial do cotidiano, atribui o papel de personagem principal da narrativa a um cavalo puxador de carroça e eleva ao posto de informação central do texto o castigo sofrido por essa personagem. Reagindo desse modo à poesia oficial, Oswald de Andrade agride a face dos adeptos dessa poesia e valoriza a face dos partidários da poesia modernista.

Assim, para dialogar com os leitores de seu tempo, agredindo ou valorizando sua face, o poeta traz para dentro do temário poético não um fato histórico e de relevância nacional ou internacional, mas um fato comum do dia a dia. Nesse fato, revela-se um conflito de

\footnotetext{
${ }^{8} \mathrm{Na}$ definição de Kerbrat-Orecchioni (2006, p. 69), "quer a chamemos de 'poder', 'hierarquia', 'dominação' ou 'relação de lugares', essa dimensão remete ao fato de que os perceiros em presença não são sempre iguais na interação".
} 


\section{Revista do SELL}

v. $4, n^{\circ} .2$

ISSN: $1983-3873$

sua época: a oposição entre um Brasil antigo, representado pela carroça e pelo carroceiro, e um Brasil novo, representado pelo bonde e pelo motorneiro. Ao proceder dessa forma, Oswald de Andrade apresenta uma nova maneira de fazer literatura, oposta à do Brasil antigo, e constrói um poema em que se refletem as tensões sociais de sua época.

Na construção do poema, também constitui uma estratégia importante nessa relação de faces o uso de uma linguagem onde predominam os elementos responsáveis pela manifestação de efeitos argumentativos e onde escasseiam os elementos que provocariam efeitos autotélicos.

Ao mesmo tempo, ao construir um poema em que aborda um fato corriqueiro, em uma linguagem distante da linguagem típica dos parnasianos e dos simbolistas, o poeta abala o lugar sagrado e, por isso mesmo, elevado que os poetas e os escritores de modo geral ocupavam (e ainda ocupam) no senso comum, segundo o qual a escrita literária é rebuscada e fruto de uma inspiração que acomete apenas alguns eleitos. Dessacralizando a poesia e o fazer poético, Oswald de Andrade torna mais equilibrados os lugares ocupados por autor e leitor, abrindo caminho para toda uma geração de poetas, como Carlos Drummond de Andrade, Murilo Mendes e João Cabral de Melo Neto.

\section{Considerações finais}

Este trabalho estudou o poema "Pobre alimária", de Oswald de Andrade, à luz do Modelo de Análise Modular do Discurso. A fim de mostrar que o poema constitui uma crítica à poesia oficial do início do século $\mathrm{XX}$, analisamos a forma de organização estratégica desse poema, revelando como o autor mobiliza uma série de recursos relacionais, informacionais, sequenciais, tópicos e composicionais para fazer a gestão das relações de faces, territórios e lugares. Ao final do percurso de análise, foi possível constatar que essas relações estão materializadas ou inscritas no texto, o qual, por revelar as tensões culturais e sociais da época de sua composição, pode ser considerado, assim como as manifestações artísticas de modo geral (Rufino, 2007), um importante documento histórico. 


\section{Revista do SELL}

v. $4, n^{\circ} .2$

ISSN: $1983-3873$

\section{Referências}

BURGER, M. L'identité négociée: "rapports de place(s)" dans un entretien télédiffusé. Cahiers de linguistique française, v. 17, 1995, p. 09-33.

BRONCKART, J. P. Atividade de linguagem, textos e discursos: por um interacionismo sóciodiscursivo. São Paulo: EDUC, 2007.

CAMPOS, H. Uma poética da radicalidade. In: ANDRADE, O. Pau-Brasil. São Paulo: Globo, 1990, p. 07-53.

CUNHA, G. X. O sequenciamento de textos como estratégia discursiva: uma abordagem modular. 2008. 250f. Dissertação (Mestrado em Linguística) - Faculdade de Letras, Universidade Federal de Minas Gerais, Belo Horizonte, 2008.

CUNHA, G. X. O impacto do contexto na construção da narrativa em uma reportagem do jornalismo político. In: NETO, F. K.; RUFINO, J. A.; BAPTISTA, M. R. (orgs.) Espaços, sujeitos e sociedade: diálogos. Barbacena: EdUEMG, 2009, p. 81-95.

CUNHA, G. X. A atuação de sequências do tipo narrativo em um texto jornalístico impresso. Revista do GEL, v. 7, 2010, p. 202-219.

CUNHA, G. X. A articulação discursiva do gênero artigo de opinião à luz de um modelo modular de análise do discurso. Filologia e Linguística Portuguesa, v. 14, 2012, p. 73-97.

CUNHA, G. X. A construção da narrativa em reportagens. 2013. 601f. Tese (Doutorado em Linguística) - Faculdade de Letras, Universidade Federal de Minas Gerais, Belo Horizonte.

FILLIETTAZ, L. Une approche modulaire de l'hétérogénéité compositionnelle du discours: Le cas des récits oraux. Cahiers de linguistique française, v. 21, 1999, p. 261-327. 


\section{Revista do SELL}

v. $4, n^{\circ} .2$

ISSN: $1983-3873$

FILLIETTAZ, L. Actions, activités et discours. 2000. 403f. Tese (Doutorado em Linguística)

- Faculdade de Letras, Universidade de Genebra, Genebra, 2000.

GOFFMAN, E. La mise em scène de la vie quotidienne: les relations em public. v. 2. Paris: Les éditions de minuit, 1973.

GOFFMAN, E. Ritual de interação: ensaios sobre o comportamento face a face. Petrópolis: Vozes, 2011.

GROBET, A. L'organisation topicale de la narration. Les interrelations de l'organisation topicale et des organisations séquentielle et compositionnelle. Cahiers de linguistique française, v. 21, 1999, p. 329-368.

GROBET, A. L'identification des topiques dans les dialogues. 2000. 513f. Tese (Doutorado em Linguística) - Faculdade de Letras, Universidade de Genebra, Genebra, 2000 .

KERBRAT-ORECCHIONI, C. Análise da conversação: princípios e métodos. São Paulo: Parábola Editorial, 2006.

MARINHO, J. H. C. O funcionamento discursivo do item "onde": uma abordagem modular. 2002. 305f. Tese (Doutorado em Linguística) - Faculdade de Letras, Universidade Federal de Minas Gerais, Belo Horizonte, 2002.

MARINHO, J. H. C; PIRES, M. S. O.; VILLELA, A. M. N. (orgs.) Análise do discurso: ensaios sobre a complexidade discursiva. Belo Horizonte: CEFET-MG, 2007.

ROULET, E.; FILLIETTAZ, L.; GROBET, A. Un modèle et un instrument d'analyse de I'organisation du discours. Berne: Lang, 2001.

RUFINO, J. A. "A Rita": documento histórico de um tempo. In: MARINHO, J. H. C; PIRES, M. S. O.; VILLELA, A. M. N. (orgs.) Análise do discurso: ensaios sobre a complexidade discursiva. Belo Horizonte: CEFET-MG, 2007, p. 87-102. 


\section{Revista do SELL}

v. $4, n^{\circ} .2$

ISSN: $1983-3873$

RUFINO, J. A. As minhas meninas: análise de estratégias discursivas em canções buarqueanas produzidas no período da Ditadura Militar. 2011. 337f. Tese (Doutorado em Linguística) - Faculdade de Letras, Universidade Federal de Minas Gerais, Belo Horizonte, 2011.

SANTIAGO, S. Bestiário. In: . Ora (direis) puxar conversa!: ensaios literários.

Belo Horizonte: Editora UFMG, 2006, p. 157-192.

SCHWARZ, R. Que horas são?: ensaios. São Paulo: Companhia das Letras, 1987, p. 1128. 